\title{
Self-Assembly of a 1-Eicosanethiolate Layer on $\operatorname{InSb}(100)$
}

\author{
Yissel Contreras $^{\mathrm{a}}$, Anthony J. Muscat ${ }^{\mathrm{a}, *}$ \\ ${ }^{a}$ Department of Chemical and Environmental Engineering, University of Arizona, Tucson, \\ Arizona 85721, USA
}

\begin{abstract}
1-eicosanethiolate molecules form relatively weak bonds with the surface of $\operatorname{InSb}(100)$ limiting the order of the self-assembled monolayer despite the long length of the alkyl chain. Heating to only $225^{\circ} \mathrm{C}$ in vacuum completely desorbed the eicosanethiolate layer from the surface based on x-ray photoelectron spectroscopy. Even after deposition times as long as $20 \mathrm{~h}$ in ethanol, the asymmetric methylene stretch was at $2925 \mathrm{~cm}^{-1}$ in the attenuated total reflection Fourier transform infrared spectrum, which is indicative of alkane chains that are incompletely ordered. Atomic force microscopy images combined with ellipsometry showed that the eicosanethiolate layer conformed to the rough $\operatorname{InSb}(100)$ starting surface (2.3 $\pm 0.2 \mathrm{~nm} \mathrm{RMS})$. The reoxidation kinetics in air of $\operatorname{InSb}(100)$ and $\mathrm{InSb}(111) \mathrm{B}$ covered with eicosanethiolate layers was the same despite the lower surface roughness of the latter $(0.64 \pm 0.14 \mathrm{~nm})$. The bond that the $\mathrm{S}$ head group makes with the substrate is the primary factor that determines the cohesiveness of the molecules on the surface. Although interactions between the alkane chains in the layer are sufficient to form a self-assembled layer, the fluidity of the molecules in the layer compromised the chemical passivation of the surface resulting in reoxidation in air after 20 minutes.
\end{abstract}

Keywords: passivation, self-assembly, liquid phase, eicosanethiol, $\operatorname{InSb}(100)$

\footnotetext{
${ }^{*}$ Corresponding author

Email address: muscat@email.arizona.edu (Anthony J. Muscat)

URL: http://muscat.chee.arizona.edu/ (Anthony J. Muscat), +1-520-626-6580 (Anthony J. Muscat)
}

Preprint submitted to Applied Surface Science

February 5, 2016 


\section{Introduction}

InSb has the smallest bandgap $(0.18 \mathrm{eV})$ of all the binary compound III-V semiconductors 1, and it can be grown in single crystal form by conventional techniques [2]. These properties lend themselves to applications that require detection and emission in the infrared and in optical filters. The wavelength range and sensitivity of infrared detectors fabricated with narrow band gap semiconductors such as $\mathrm{InSb}$ are superior to those based on $\mathrm{Pb}, \mathrm{Si}$, and $\mathrm{Ge}$ [3. Due to its high electron mobility and conductivity, InSb is a potential material for low power field effect transistors [4, 5]. InSb is known to rapidly form a layer of complex and nonstoichiometric oxides when exposed to air [6]. Since the interface between InSb and its oxides is electrically defective [7, these oxides must be removed. A simple approach to cleaning semiconductor surfaces is the thermal desorption of contaminants. Heating InSb desorbs the Sb oxides, but the temperature required to remove the In native oxides is close to the melting point of $\operatorname{InSb}\left(\sim 527^{\circ} \mathrm{C}\right)[8$. Cleaning $\operatorname{InSb}(100)$ substrates with radio frequency-generated hydrogen radicals at $275{ }^{\circ} \mathrm{C}$ removed the native oxides and left an In-rich surface while maintaining a root mean square (RMS) surface roughness of $0.5 \mathrm{~nm}[8]$. Clean $\operatorname{InSb}(100)$ surfaces with roughness values of 0.15 $\mathrm{nm}$ [9] and $0.28 \mathrm{~nm}$ [10] were obtained when oxidized substrates were exposed to atomic hydrogen at $250{ }^{\circ} \mathrm{C}$. Other approaches include gas phase removal of InSb oxides using $\mathrm{TiCl}_{4}$, which selectively removes In [11. Gas phase mixtures of $\mathrm{HF}$ and water vapor partially removed the native oxides while maintaining a surface roughness of $0.45 \mathrm{~nm}$ without excessive Sb enrichment [12].

The presence of dangling bonds at the semiconductor-oxide interface creates surface states, which affect the ability to precisely control the charge carriers in the near surface region and to obtain a small recombination velocity [13. The surface state density of InSb is very large $\left(\sim 1 \times 10^{12} \mathrm{~cm}^{-2} \mathrm{eV}^{-1}\right.$ [14] $)$ compared to that of silicon $\left(\sim 1 \times 10^{10} \mathrm{~cm}^{-2} \mathrm{eV}^{-1}[15]\right)$. In order for InSb and other 
III-V semiconductors to compete with $\mathrm{Si}$ in high volume manufacturing applications, a passivation layer that satisfies these dangling bonds is required [14]. The layer must prevent reactions when the semiconductor surface is exposed to air or contaminants (chemical passivation) as well as eliminate and prevent interfacial states from forming, while creating a barrier for the loss of electrons (electrical passivation) 16. For a device application, a protective layer that can 35 be removed without compromising the integrity of the substrate is desirable.

Liquid phase processes to chemically etch the native oxides and passivate semiconductor surfaces are convenient because of their simplicity and low cost. The use of chalcogenide (sulfur and selenium) atoms to modify the surface of III-V semiconductors decreases the density of surface states in the band gap and 40 provides temporary protection against oxidation [17]. A thin S or Se overlayer can also serve as a source of dopants [18, 19]. When $\operatorname{InSb}(001)$ and $\operatorname{InSb}(111) \mathrm{B}$ surfaces were cleaned with atomic hydrogen and modified with a sulfur layer in an electrochemical cell for $30 \mathrm{~min}$ at $\sim 275{ }^{\circ} \mathrm{C}$, x-ray photoelectron spectroscopy (XPS) revealed the formation of Sb-S and In-S bonds [19. High resolution electron energy loss spectroscopy (HREELS) showed and an increase in the surface Fermi level for both crystal orientations with flat band conditions (passivation of the electron depletion) in the case of $\operatorname{InSb}(001)$ and electron accumulation in the case of $\operatorname{InSb}(111) B$, with an estimated sulfur coverage of $\sim 2$ monolayers. Sodium sulfite $\left(\mathrm{Na}_{2} \mathrm{~S}\right)$ was used to etch the native oxides leaving an In-S layer 50 [20]. The $\operatorname{InSb}(100)$ substrates were immersed in $1 \mathrm{M} \mathrm{Na}_{2} \mathrm{~S}$ at $45^{\circ} \mathrm{C}$ for $7 \mathrm{~min}$, and XPS spectra of the freshly treated samples showed the disappearance of oxygen and oxide peaks and the appearance of an $\mathrm{Sb}$ sulfide peak in the $\mathrm{Sb}$ $3 \mathrm{~d}_{5 / 2}$ core-level spectrum. There were no $3 \mathrm{~d}_{5 / 2}$ high binding energy peaks due to sulfide or oxide states after annealing the substrate at $150{ }^{\circ} \mathrm{C}$ in ultra-high 55 vacuum. In another study, InSb(111)A substrates were immersed in ammonium sulfide, $\left(\mathrm{NH}_{4}\right)_{2} \mathrm{~S}$, solutions at room temperature [21]. Atomic force microscopy (AFM) and XPS showed that a 1 min immersion in $10 \%\left(\mathrm{NH}_{4}\right)_{2} \mathrm{~S}$ yielded a surface roughness of $0.56 \mathrm{~nm}$ (initially $0.51 \mathrm{~nm}$ ) and oxygen levels below detection limits immediately after sulfide deposition. The inert layer was almost 
completely removed by annealing in vacuum at $300{ }^{\circ} \mathrm{C}$. Oxidized $\operatorname{InSb}(100)$ substrates were treated in $\left(\mathrm{NH}_{4}\right)_{2} \mathrm{~S}$ solutions in water and isopropanol at room temperature 22]. After a 35 min treatment in a 1:10 solution of $\sim 20 \%\left(\mathrm{NH}_{4}\right)_{2} \mathrm{~S}$ diluted in isopropanol, a smaller $\mathrm{O}$ 1s peak than that obtained with an equivalent concentration of $\left(\mathrm{NH}_{4}\right)_{2} \mathrm{~S}$ in water was observed by inspection of the $\mathrm{Sb}$ 65 3d XPS region.

To address the issue of the short-term stability of sulfide layers and to better understand the mechanism of sulfur passivation of GaAs, organic approaches involving aromatic thiols, aliphatic thiols, and aliphatic dithiols were studied [23]. Carbonaceous layers are hydrophobic and can present a physical barrier to the diffusion of molecular oxygen and water in air. The sulfur head group tethers the organic tail group to the surface. An enhancement in the photoluminescence indicating a reduction of surface states was observed when GaAs(100) substrates were immersed in solutions containing ethanedithiol and 4-Cl-thiophenol. Since that early work there are several reports of the chemical passivation of GaAs using self-assembled monolayers (SAMs) of organic molecules with thiol head groups $24,25,26,27,28,29,30$. In one of these studies, eight linear alkanethiols with carbon chains lengths (n) between 12 and 19 were compared in the formation of SAMs on clean GaAs(001) in ethanol solutions [26]. The carbon coverage calculated from XPS analysis agreed with the theoretical prediction so for constant monolayer coverage for $n \geq 15$. Furthermore, for $n \geq 17$ the percentage of As oxide in the As 3d XPS region after brief air exposures was below detection limits. The position of the $-\mathrm{CH}_{3}$ antisymmetric stretch in the Fourier transform infrared (FTIR) spectrum reached a minimum of $2917 \mathrm{~cm}^{-1}$ indicative of a solid-like layer of thiol molecules. A solid layer that is densely packed and highly ordered can act as a diffusion barrier against molecular oxygen and water vapor. A peak position greater than $2919 \mathrm{~cm}^{-1}$ is associated with a disordered liquid-like state of adsorbed thiol molecules based on transmission measurements in the same work.

We reported that long deposition times were necessary to form an alkanethi90 olate layer on $\operatorname{InSb}(100)$ that protected the surface, but oxide regrowth was 
prevented for only $3 \mathrm{~min}$ [31. We suggested that the atomically rough starting surface introduced defects in the alkanethiolate layer and this contributed to the rapid reoxidation. To test this idea, we formed alkanethiolate layers in this study on both $\operatorname{InSb}(100)$ and an $\operatorname{InSb}(111) B$ surface that had less than half the average roughness, and found that the reoxidation kinetics were the same. Despite optimizing the solvent, immersion time, and surface preparation steps to form the self-assembled layer based on ellipsometry, XPS, and attenuated total reflection (ATR) FTIR measurements, the bond that the alkanethiolate makes with InSb is weak, which compromises the protection of the surface.

\section{Experimental}

Semiconductor grade acetone, hydrofluoric acid (HF, 49\%), hydrochloric acid $(\mathrm{HCl}, 37 \%)$, isopropyl alcohol (IPA, VLSI grade) and hydrogen peroxide $\left(\mathrm{H}_{2} \mathrm{O}_{2}\right.$, $30 \%$ ), were obtained from Honeywell. Ethanol (anhydrous, 99.5\%), toluene (anhydrous, $99.8 \%$ ), and ammonium hydroxide (28.0-30\%, $\mathrm{NH}_{3}$ basis), were purchased from Sigma Aldrich, and chloroform $\left(\mathrm{CHCl}_{3}, 99.8 \%\right)$ and 1-eicosanethiol (ET, 98\%), from Alfa-Aesar. Cyclohexane (99\%) was obtained from Fisher Scientific. All the solvents and reagents were used as received. The deionized water (DIW) water had a resistivity of $18.2 \mathrm{M} \Omega-\mathrm{cm}$.

$\operatorname{InSb}(100)$ (Xiamen) and InSb(111)B (Firebird Semiconductors) wafers (undoped, $51 \mathrm{~mm}$ diameter, $500 \mu \mathrm{m}$ thickness) were cleaved into $14 \times 18 \mathrm{~mm}^{2}$ pieces and degreased by sonication in acetone and DIW for 1 min each, followed by a DIW rinse and a nitrogen dry. The InSb substrates out of the box were covered in a cap layer that was etched using a sequential liquid phase process. Each sample was immersed for $1 \mathrm{~min}$ in $0.28 \mathrm{M}$ HF with a $30 \mathrm{~s}$ rinse in DIW and nitrogen dry, followed by a 2 min immersion in $1.0 \mathrm{M} \mathrm{H}_{2} \mathrm{O}_{2}$ with DIW rinse and nitrogen dry. This process was performed twice to produce a clean starting surface.

The samples were finished with halogen acid etches - 1 min each in 0.28 $\mathrm{M} \mathrm{HF}$ and $1.0 \mathrm{M} \mathrm{HCl}$ - and immersed in the solution containing eicosanethiol. 

liquid layer was carried over between steps to try and keep the surface free of oxides. Samples were placed vertically in stirred solutions of $0.1 \mathrm{mM}$ eicosanethiol dissolved in ethanol for $20 \mathrm{~min}, 20 \mathrm{~h}$, or $48 \mathrm{~h}$. To compare deposition on the (100) and the (111)B crystal planes an eicosanethiol concentration of $0.4 \mathrm{mM}$ covered and less than $10 \%$ of the solution evaporated during the longest processes. IPA, toluene, chloroform, and cyclohexane were also investigated as solvents for eicosanethiol. After the thiol step, the samples were swished for 20-30 s in the corresponding solvent to remove physisorbed molecules and dried with nitrogen. The shortest time that samples were exposed to air was $3 \mathrm{~min}$ between drying and loading into a vacuum chamber for analysis.

The thickness of the overlayer on the InSb surface after passivation was measured using a J.A. Woollam M-2000 spectroscopic ellipsometer at an incident angle of $75^{\circ}$. A two-slab model was used consisting of an InSb substrate covered by InSb oxide even though an ET layer may also have been present alone or in combination. The measured thickness is approximate as the refractive index of alkanes $\left(\sim 1.5,32\right.$ ) is not equal to that of $\mathrm{Sb}$ oxide $\left(2.80\right.$ for $\left.\left.\mathrm{Sb}_{2} \mathrm{O}_{3}, 33\right]\right)$. All errors are reported with $95 \%$ confidence.

X-ray photoelectron spectroscopy (XPS) was performed on a Physical Electronics system equipped with a non-monochromatic dual-anode $\mathrm{Al} / \mathrm{Mg} \mathrm{K} \alpha$ source and a double-pass cylindrical mirror analyzer (Model 549). High-resolution spectra were obtained using the $\mathrm{Al} \mathrm{K} \alpha$ source $(1486.6 \mathrm{eV})$ with $0.1 \mathrm{eV}$ steps and a pass energy of $50 \mathrm{eV}$. Sample charging was compensated by referencing to the $\mathrm{Sb}-\mathrm{In}$ photoelectron line in the $\mathrm{Sb} 3 \mathrm{~d}_{3 / 2}$ region at $537 \mathrm{eV}$. A Shirley background was subtracted from each peak envelope and the result fit with a Voigt lineshape using custom algorithms and built-in packages in Igor Pro (Wavemetrics, Inc.). To obtain XPS data on the reoxidation kinetics of InSb after different treatments, a single sample was analyzed repeatedly after multiple ambient exposures.

Attenuated total reflection (ATR) FTIR spectra were recorded for InSb 
coupons $50 \times 10 \mathrm{~mm}$ in size with a single beam spectrometer (Nicolet Nexus 670) equipped with a nitrogen-cooled MCT detector. Spectra were collected within the first $10 \mathrm{~min}$ of exposure of the passivated sample to atmosphere, and a background was subtracted consisting of the atmosphere in the analysis chamber after purging with nitrogen for 10 min. Each spectrum consisted of co-adding 200 scans at a resolution of $4 \mathrm{~cm}^{-1}$. A trapezoidal Ge element $(50 \times$ $10 \times 3 \mathrm{~mm}$ with $45^{\circ}$ bevels) was used as the internal reflection element. The angle of incidence of the beam was $60^{\circ}$. ATR correction of the collected spectra was performed with the analysis software OMNIC (v.6.2).

Surface topography was imaged by atomic force microscopy (AFM) using a Multimode V station (Bruker) in tapping mode. Root mean square (RMS) roughness values were calculated over $500 \times 500 \mathrm{~nm}^{2}$ areas with a scan rate of $1 \mathrm{~Hz}$ and a resolution of 512 pixels/line. The aluminum coated tips (TESPA Bruker AFM probes) had a nominal force constant of $42 \mathrm{~N} / \mathrm{m}$; first-order planefitting compensated for tilt.

Heating of the sample was done in vacuum and the temperature measured using a type-K thermocouple spot-welded to a $0.26 \mathrm{~cm}^{2}$ piece of Ta foil pressed to the sample using a linear motion feedthrough.

\section{Results and Discussion}

Eicosanethiol contains a chain of 20 carbon atoms, which is the longest that is available commercially. The presence of a hydrophobic chain and the hydrophilic thiol head group suggest that the polarity of the solvent plays an important role in film deposition. In a study of the formation of a hexadecanethiolate layer, which contains a shorter chain, on the surface of $\operatorname{GaAs}(001)$, Huang et al. concluded that a 1:1 mixture of ethanol and water promoted interactions among the thiol molecules, which increased the quality of the SAM based on FTIR and slowed down surface reoxidation as shown by XPS 24]. Using chloroform as the solvent weakened the interactions between alkane chains producing a poor quality layer and forming $\mathrm{Ga}_{2} \mathrm{O}_{3}$, yet the concentration of sur- 

constants of about 20 .

\begin{tabular}{l|c} 
Solvent & Dielectric constant \\
\hline Cyclohexane & 2.02 \\
Toluene & 2.38 \\
Chloroform & 4.81 \\
Isopropanol & 20.2 \\
Ethanol & 25.3
\end{tabular}

Table 1: Dielectric constants of the solvents used to deposit ET [33].

The initial thickness of the overlayers shown in Figure 1 was measured after exposure to air for $3 \mathrm{~min}$, which was the shortest time possible after the final liquid step. The thickness varied from $19.4 \pm 0.6 \AA$ for chloroform to $46 \pm 3 \AA$ for cyclohexane. The initial thickness in chloroform was approximately the same as that for a control experiment in pure ethanol without the thiol. We conclude that the thiol coverage was low or nonexistent using $\mathrm{CHCl}_{3}$ and the thickness change is due only to reoxidation of the surface. A control experiment consisting of a 20 min immersion in pure ethanol after surface cleaning shows that InSb oxidizes rapidly. An oxide that is $24 \AA$ thick forms in $3 \mathrm{~min}$ in air.

The results in ethanol, IPA, and toluene are clustered together at an initial thickness of 32-35 $\AA$. Since the length of an ET molecule is $26.9 \AA$ (calculated using ChemDraw), the difference is due to physisorbed ET molecules, reoxidation of the surface, or inaccuracies in the ellipsometry model. If the first ET layer is bound $\mathrm{S}$ end down with the chains extending outward from the surface at an angle with respect to the surface normal, then chains may be physisorbed 
to the hydrophobic methyl groups exposed to the solution. The angle between the ET molecules and the substrate could not be obtained from ellipsometry because the measured thickness was greater than the length of the molecule. The ellipsometry model that we used did not distinguish between the thiol layer and surface oxide since there is not enough contrast in the refractive indexes. Moreover, different scenarios are possible for the relative position and surface coverages of the oxide and the thiol layer. Since the initial thickness in cyclohexane is $46 \AA$ or almost twice the length of ET, either a bilayer or patches of multilayers and regrown oxides contribute. Over time in air up to 60 min the thickness increases to about $55 \AA$ A. Ethanol, IPA, and toluene yielded a starting thickness closer to the length of ET and provided better control of the thickness over time, increasing to $36-38 \AA$ over the course of one hour in air.

XPS was used to differentiate between oxide regrowth and thiol deposition. ${ }_{215}$ Figure 2 shows the XPS spectra after immersion in the thiol solution for $60 \mathrm{~min}$ using chloroform as the solvent and the standard $20 \mathrm{~min}$ in toluene, ethanol, and IPA. The spin-orbit coupled bulk $\mathrm{Sb} 3 \mathrm{~d}_{5 / 2}$ state is at $527.7 \mathrm{eV}$ (in comparison, previous works report $528.0 \mathrm{eV}[20,21])$ and the $\mathrm{Sb} 3 \mathrm{~d}_{3 / 2}$ state was fixed at $537.0 \mathrm{eV}$ (reported at $537.3 \mathrm{eV}$ [21]). The bulk In $3 \mathrm{~d}_{5 / 2}$ state was assigned at $444.0 \mathrm{eV}$ (444.0 eV for a native oxide surface and $444.4 \mathrm{eV}$ for a sulfur-treated surface have been reported [20]) and the In $3 \mathrm{~d}_{3 / 2}$ state is at $451.5 \mathrm{eV}$. The states at $530.5 \mathrm{eV}$ and $540.0 \mathrm{eV}$ to higher binding energies are due to $\mathrm{Sb}$ oxide and sulfide. The O 1s state overlaps the Sb-O and Sb-S states, and the peak around $530.5 \mathrm{eV}$ contains contributions from all three states. The presence of $\mathrm{Sb}$ oxide in the $3 \mathrm{~d}_{5 / 2}$ state has been reported at $530.8 \mathrm{eV}$ and $\sim 530.3 \mathrm{eV}$ 20] and, specifically, $\mathrm{Sb}^{3+}$ contributions were resolved at $530.5 \mathrm{eV}$ and $\mathrm{Sb}^{5+}$ at $531.4 \mathrm{eV}$ [21]. O 1s contributions have been found at $\sim 531 \mathrm{eV}$ [19] and $\sim 532 \mathrm{eV}$ [21], and Sb-sulfide bonding has been reported at $530.4 \mathrm{eV}$ [20] and $\sim 530 \mathrm{eV}$. No additional oxidation states were resolved for In due to the small binding energy difference between the bulk and the $\operatorname{In}_{2} \mathrm{O}_{3}$ states. Furthermore, the bulk In peaks did not shift to higher binding energy, suggesting that the surface was terminated with $\mathrm{Sb}$ atoms. Since the $530.5 \mathrm{eV}$ peak is larger than 
the bulk peak at $527.7 \mathrm{eV}$ when either chloroform or toluene was used as the solvent (Figure $2 \mathrm{a}$ and $\mathrm{b}$ ) and $\mathrm{S}$ was not detected on the surface, oxide must have regrown. The presence of the $\mathrm{O}$ Auger state at $975 \mathrm{eV}$ supports this conclusion. The origin of the slightly thicker oxide when toluene was used compared to chloroform is not clear from these data because sulfur was not detected in either experiment and the carbon XPS peaks are similar. Although ellipsometry shows that the overlayer thickness is the same in toluene and the alcohols, the composition of the layer made using toluene must be primarily $\mathrm{Sb}$ oxide. The substrates immersed in toluene solutions have more oxide than those treated in $\mathrm{CHCl}_{3}$ from comparison of the O Auger state. Since XPS shows that $\mathrm{CHCl}_{3}$ does not promote bonding of $\mathrm{ET}$ to InSb, but still slows down the oxidation compared to the toluene solution and the control experiment, $\mathrm{CHCl}_{3}$ itself could be chemisorbed on the surface. $\mathrm{A} \mathrm{Cl} 2 \mathrm{p}$ peak was detected only after immersion in $\mathrm{CHCl}_{3}$ (data not shown). Control experiments showed that surfaces finished in $\mathrm{HCl}$ and immersed for $20 \mathrm{~min}$ in pure toluene, chloroform, and ethanol had Auger peak areas after $4 \mathrm{~min}$ of air exposure that were a factor of two or more higher than when the alkanethiolate was present (data not shown). Less oxide was formed when pure ethanol was used in the control experiments than the other solvents.

Using IPA or ethanol to dissolve the thiol reduced the size of the higher binding energy $3 \mathrm{~d}$ peaks due to oxidized $\mathrm{Sb}$, and produced both a detectable $\mathrm{S}$ peak at $162-163 \mathrm{eV}$ and a larger $\mathrm{C}$ peak at $284.5 \mathrm{eV}$. The $\mathrm{C}$ states are much 255 stronger in the case of the two alcohols because of the presence of the long $\mathrm{C}$ chain attached to the thiol. The $\mathrm{C}$ peak observed when using toluene is likely to be due to background contamination or ET deposition at submonolayer coverage. The $\mathrm{Sb} 3 \mathrm{~d}_{5 / 2}$ state in Figure $2 \mathrm{c}$ and $\mathrm{d}$ is shifted slightly lower in binding energy to $530 \mathrm{eV}$ because the state is due primarily to $\mathrm{S}$. The state at $162 \mathrm{eV}$ was assigned to sulfide. The $\mathrm{O}$ Auger state can just be distinguished above the background noise. Based on these results the two alcohols yielded similar results as on GaAs [24, and we chose ethanol as the solvent for all of the following thiol experiments. 
The thin liquid layer of aqueous $\mathrm{HCl}$ carried over into the solution of ET and experiments in the study.

The same criterion was used to investigate the impact of lengthening the time of immersion in the thiol solution. Figure $3 \mathrm{f}$ and $\mathrm{g}$ show the ratios calculated for 
ET dissolved in ethanol. The ratio of the $3 \mathrm{~d}_{5 / 2}$ bulk to oxide peak areas rose to 3.7 at $20 \mathrm{~h}$ but fell to 2.7 after $48 \mathrm{~h}$. Also there was a visible film on the surface after immersion for $48 \mathrm{~h}$. Although the statistical variation was high, these results were used to define our best performing process on $\operatorname{InSb}(100)$, namely a dissolved in ethanol for $20 \mathrm{~h}$. XPS spectra are shown in Figure 4 comparing this process (Figure $4 \mathrm{~b}$ ) to the $20 \mathrm{~min}$ process (Figure $4 \mathrm{a}$ ) and to a $20 \mathrm{~h}$ process but after $4 \mathrm{~h}$ of air exposure (Figure $4 \mathrm{c}$ ). The peaks that appear in the $\mathrm{C} 1 \mathrm{~s}$ and $\mathrm{S} 2 \mathrm{p}$ region are similar for the two immersion times, and there is no shift Auger state is close to background noise in both cases. The difference appears in the $\mathrm{Sb} 3 \mathrm{~d}$ region, where the high binding energy peaks are shifted towards 530 $\mathrm{eV}$ due to the lower coverages of Sb oxides. The smallest high binding energy peaks in the region correspond to the $20 \mathrm{~h}$ process, as already shown in Figure surface oxidation. There is less sulfide in the $\mathrm{S} 2 \mathrm{p}$ region, and an additional state appeared between sulfide and where sulfate is expected. The $\mathrm{C} 1$ s state is smaller and shifted to a higher binding energy due to oxidation. These changes are the result of the desorption and degradation of the thiol layer. A distinct peak appeared in the $\mathrm{O}$ Auger region. The In $3 \mathrm{~d}$ peaks shifted to higher binding energy due to the formation of $\mathrm{In}_{2} \mathrm{O}_{3}$, and the high binding energy $\mathrm{Sb} 3 \mathrm{~d}$ peaks dominate those of bulk Sb. The high binding energy peak in the $3 \mathrm{~d}_{5 / 2}$ region has shifted back to $530.5 \mathrm{eV}$. The thiol layer blocked oxygen and water vapor from diffusing to the InSb surface for $3 \mathrm{~min}$, but after $4 \mathrm{~h}$ most of the passivation layer desorbed and the surface was almost completely reoxidized.

To better understand the structure of the thiol layer deposited by a long immersion time, the density of the ET layer on the InSb(100) surface after the $20 \mathrm{~h}$ process was probed with FTIR. Attenuated total reflection was used because InSb absorbs strongly in the infrared. Figure 5 compares the ATR 325 spectrum of an InSb sample after surface cleaning and reoxidation to that of 
the $20 \mathrm{~h}$ process. Peaks characteristic of the alkane chain of ET are present at $2963 \mathrm{~cm}^{-1}$ (asymmetric stretch of methyl), $2925 \mathrm{~cm}^{-1}$ (asymmetric stretch of methylene), $2877 \mathrm{~cm}^{-1}$ (symmetric stretch of methyl), and $2847 \mathrm{~cm}^{-1}$ (symmetric stretch of methylene). The weak absorbances observed, in comparison to those reported for 1-octadecanethiol (ODT) layers adsorbed on GaAs(100) [27], indicate that the ET layer on $\mathrm{InSb}$ is only partially ordered. There are contributions at $2963 \mathrm{~cm}^{-1}$ and $2925 \mathrm{~cm}^{-1}$ due to intrinsic absorption from the clean InSb substrate. When layers of 1-nonadecanethiol were deposited on $\operatorname{GaAs}(001)$ surfaces, vibrational modes were found at $2967 \mathrm{~cm}^{-1}$ (asymmetric stretch of methyl), $2917 \mathrm{~cm}^{-1}$ (asymmetric stretch of methylene), $2877 \mathrm{~cm}^{-1}$ (symmetric stretch of methyl), and $2850 \mathrm{~cm}^{-1}$ (symmetric stretch of methylene) [26]. Furthermore, a transition of the phase of the alkane chains from liquid to solid is associated with a shift of the asymmetric methylene peak from 2928 $\mathrm{cm}^{-1}$ to $2917 \mathrm{~cm}^{-1}$ [35. The peak at $2925 \mathrm{~cm}^{-1}$ in Figure 5 shows that the alkane chains are still in a liquid like phase and not well-ordered as in a solid. The thickness of an eicosanethiolate layer deposited for $20 \mathrm{~h}$ on $\mathrm{InSb}$ measured with ellipsometry was $41.6 \pm 2.8 \AA$ after $4 \mathrm{~min}$ of air exposure. The measured layer thickness $4 \mathrm{~min}$ after the $20 \mathrm{~min}$ process was $34.6 \pm 0.6 \AA$ (Figure 1). Since XPS analysis indicates that InSb surfaces treated for $20 \mathrm{~h}$ have a lower oxide 345 coverage than those treated only for $20 \mathrm{~min}$, the difference of $\sim 7 \AA$ in the measured thickness must be due to the physisorption of ET at the longer deposition time. A portion of this increase could be due to a denser eicosanethiolate layer but molecules physisorbed to this layer also contribute. Incubation times of at least $20 \mathrm{~h}$ were necessary to form highly ordered and dense octadecanethiolate layers on $\operatorname{GaAs}(001)$ 36.

Self-assembled monolayers of thiols have been used to modify III-V surfaces, primarily GaAs. After the first studies that showed photoluminescence enhancement of $\operatorname{GaAs}(100)$ with short chain thiols [23], SAMs prepared with longer alkanethiols have been analyzed with XPS ([24, 26, 27, 29, 30, 36, 37]), 355 FTIR ([24, 27, 29, 30, 36, 38]), photoluminescence $([24$, 29, 37]), contact angle $([30,36,37])$, and other techniques. In one of these studies, the effect of 
the deposition solvent on the SAM quality was studied [30]. A mixture of water and ethanol in a proportion of 1:1 instead of pure ethanol improved the conformational order of 16-mercaptohexadecanoic acid on GaAs(001) by FTIR analysis (the asymmetric methylene stretch shifted from $2922.7 \mathrm{~cm}^{-1}$ to 2918.5 $\mathrm{cm}^{-1}$ ). Less oxide states were found by XPS in the Ga 3d and As 3d regions when using the water and ethanol mixture. Adsorbate packing-induced stress due to intermolecular forces was found to play a critical role in the ordering of ODT layers on GaAs(111), (110), and (100) [27]. GaAs(111)A substrates, which are believed to be less prone to surface rearrangement, yielded methylene stretches at higher wavenumbers in the FTIR and weaker absorbances than the other studied surfaces. Vapor deposition of ODT layers on GaAs(100) surfaces showed superior structural properties compared to those of layers deposited in dilute ODT solutions in ethanol (lower Ga 3d and As 3d oxide levels and a 370 larger contact angle that changed less than $10 \%$ after 4 months of exposure to air) [37.

One possibility for the relatively poor ordering of the ET layer on $\operatorname{InSb}(100)$ is surface roughness. The topography of the surfaces after cleaning (sequential oxide etching) and reoxidation and after the $20 \mathrm{~h}$ ET deposition process was measured using AFM (Figure 6). The surface roughness was $2.3 \pm 0.2 \mathrm{~nm}$ for the wafer out of the box, $3.8 \pm 1.2 \mathrm{~nm}$ after cleaning and reoxidation only, and 2.8 (single measurement) $\mathrm{nm}$ after the adsorption of an ET monolayer and $20 \mathrm{~min}$ of air exposure. Even before processing, the surface of $\mathrm{InSb}$ is rough on an atomic scale. The sequential cleaning processes introduce more variability in the surface topography, which could be the result of selective etching in the $\mathrm{H}_{2} \mathrm{O}_{2}$ and $\mathrm{HCl}$ cleaning steps. This could explain the islands in the AFM image observed after cleaning and reoxidation only (Figure 6b). The surface roughness previously reported for InSb cleaning is $\sim 0.7 \mathrm{~nm}$ after liquid phase HF etching and as low as $\sim 0.5 \mathrm{~nm}$ for gas phase $\mathrm{HF} / \mathrm{H}_{2} \mathrm{O}$ etching $(\sim 0.5 \mathrm{~nm}$ for the untreated surface) 385 11.

The topography after cleaning is representative of the surface that is immersed into the thiol solution. The ET layer does not increase the roughness 
but instead appears to smooth out the islands (Figure 68). The variable topography could cause small islands of well-ordered ET to be mixed with less ordered patches, which is consistent with the ATR-FTIR data. An atomically rough InSb surface is consistent with the relatively poor quality thiol monolayer that formed. A model to explain the shift to higher wavenumbers of the symmetric and asymmetric methylene stretch in FTIR for dodecanethiol on roughened $\mathrm{Si}(100)$ surfaces suggests that annealing and gap filling occur when depositing layers on smooth surfaces at high temperature $\left(200^{\circ} \mathrm{C}\right)$, but on rough surfaces $(\mathrm{RMS}=7.3 \mu \mathrm{m})$ the steps and defects limit the ordering and the overlap of alkane chains at the steps (the position of the asymmetric methylene stretch was independent of the deposition temperature on the rough surface) [39. If a surface is atomically rough, then more binding sites are exposed per unit area and the number of sites not covered by thiol increases yielding partial passivation [40]. Roughness could also contribute to the thickness of $41.6 \pm 2.8 \AA$ measured by ellipsometry after the $20 \mathrm{~h}$ process and explain why the eicosanethiolate layer is thicker than one molecule.

To test how the thiol layer forms on a smoother surface, the reoxidation kinetics of $\operatorname{InSb}(100)$ and $\operatorname{InSb}(111) B$ covered with ET layers were studied by exposing the substrates to air for different lengths of time. The (111)B surface was chosen because this crystal plane is terminated by $\mathrm{Sb}$ atoms [41]. Based on the XPS, the (100) surface is terminated by Sb after the etch in the halogen acids. The $\mathrm{Sb}$ to $\mathrm{In}$ ratio after the last $\mathrm{HCl}$ step and water rinse was 2.75 . The roughness of the $\mathrm{InSb}(111) \mathrm{B}$ surface was $0.64 \pm 0.14 \mathrm{~nm}$, which is lower than the $\operatorname{InSb}(100)$ that we used. After cleaning, samples were immersed in $0.4 \mathrm{mM}$ ET for $20 \mathrm{~min}$ followed by ambient exposure for increasing periods of time. The results are shown in Figure 7. Based on the $\mathrm{Sb} 3 \mathrm{~d}_{5 / 2}$ region, which contains the contribution from the $\mathrm{O}$ 1s peak, the two surfaces oxidized at the same rate 415 (slope of the unfilled points in Figure $7 \mathrm{a}$ ). The ET layers slowed the initial rate of reoxidation compared to control experiments in which $\operatorname{InSb}(100)$ and $\mathrm{InSb}(111) \mathrm{B}$ were finished with $\mathrm{HCl}$ and rinsed in ethanol before being exposed to air (filled points at $3.5 \mathrm{~min}$ ). An alternative control experiment in which 
$\mathrm{InSb}(100)$ was finished with $\mathrm{HCl}$ but not rinsed appeared to slow the oxidation rate (filled circles in Figure 7a). Chlorine was detected by XPS (data not shown) and could passivate the surface.

In Figure 7b, the area under the corresponding $\mathrm{O}$ Auger peaks is plotted for different air exposure times. Although less sensitive than the corresponding XPS states, the $\mathrm{O}$ Auger peak contains contributions from all oxygen species and is not affected by the presence of the sulfide. Reoxidation was slowest for InSb treated with ET and the rate of oxidation was the same for the (100) and the (111)B surfaces. In comparison, the Auger data show that the surface reoxidized faster after the $\mathrm{HCl}$ last without a rinse. This trend is masked in the XPS data in Figure $7 \mathrm{a}$ by the higher background due to the presence of $\mathrm{S}$ on the thiol-treated 430 surfaces. Care has to be exercised when comparing the Auger peak areas because this state is attenuated only on the samples containing the alkanethiolate layer. However, the $20 \mathrm{~h}$ ET process produced both the smallest $\mathrm{Sb} 3 \mathrm{~d}_{5 / 2}$ peak area ratios and the smallest $\mathrm{O}$ Auger peak areas. The alkanethiolate layer formed by the $20 \mathrm{~h}$ process was the most effective at slowing reoxidation of the surface even after $4 \mathrm{~h}$ of air exposure (point marked by arrow). Moreover, based on the Auger peak area, the alkanethiolate layer prevented oxide regrowth for $20 \mathrm{~min}$.

The identical reoxidation rates measured for the (100) and (111)B planes shows that surface roughness can not explain the short protection times of only about $20 \mathrm{~min}$. The forces driving molecular self-assembly are the result of the interaction of the $\mathrm{S}$ head group with the substrate and the interactions between molecules within the layer. Both surfaces are terminated by Sb after cleaning, hence the bond between the thiol and these planes should be similar. The strength of the bond between the $\mathrm{S}$ atom in thiols and metal atoms varies widely depending on the structure of the thiol 42 . The S-Sb bond strength 445 is consistently reported at $\sim 379 \mathrm{~kJ} / \mathrm{mol}$ [33, 43]. For comparison, the $\mathrm{S}-\mathrm{As}$ bond is stronger with values of $\sim 380 \mathrm{~kJ} / \mathrm{mol}$ [33, $\sim 478 \mathrm{~kJ} / \mathrm{mol}$ [43, and a theoretical estimate of $588 \mathrm{~kJ} / \mathrm{mol}$ [4] reported. The stronger sulfur-metal bond is consistent with the longer time of about 2 weeks to reoxidize $\operatorname{GaAs}(001)$ covered with an octadecanethiol layer (determined by the absence of As and Ga 
oxide peaks in the XPS 3d regions) 36.

Another aspect to consider is the cohesive energy of the alkanethiolate molecules on the surface. The lattice parameter of InSb is $6.48 \AA$ and that of GaAs is 5.65 $\AA$ [33. The substrate surface atom densities computed from these values are $6.0 \times 10^{14} / \mathrm{cm}^{2}$ for $\mathrm{InSb}$ and $7.9 \times 10^{14} / \mathrm{cm}^{2}$ for GaAs. The surface of $\mathrm{InSb}$ is more open than GaAs exposing the underlying layer of atoms. Alkanethiolate molecules tethered to the surface by S may be farther apart on InSb than on GaAs depending on how the surface restructures. The alkanethiolate molecules that fit between the tethered moieties defined by $\mathrm{S}-\mathrm{Sb}$ bonds interact with the second layer of substrate atoms, which on the (100) plane are In atoms. Sulfur makes a weaker bond to In than to $\mathrm{Sb}$ [33, 43. The weaker bonding and longer interaction length - since the In atoms are, in principle, in the second layer-lowers the average bond energy of the alkanethiolate molecules with the surface. The weaker average bonding between the $\mathrm{S}$ head group and the substrate makes the alkanethiolate layer more fluid, which is supported by the FTIR data. Moreover, the van der Waals attraction between alkane chains is insufficient to compensate for the weak bonding between $\mathrm{S}$ and the substrate.

Another measure of cohesion of the self-assembled layer is the energy required to separate or desorb molecules from the surface. To test the removal of the protective layer in vacuum and obtain an estimate of the bond strength, $40 \operatorname{InSb}(100)$ covered with an ET layer using the $20 \mathrm{~h}$ process was heated and analyzed afterward with XPS. Comparison of Figure 8 and b shows peaks consistent with the formation of a thiol monolayer that protects the surface from a short (3-5 $\mathrm{min})$ exposure to air as we described previously. The presence of S in the $2 \mathrm{p}$ region and the small peaks at high binding energy in the $\mathrm{Sb} 3 \mathrm{~d}$ state that are shifted lower in energy compared to oxides are characteristic of the thiol layer. Notice the attenuation of the Sb and In signal intensities due to the presence of the ET layer. After heating to approximately $225^{\circ} \mathrm{C}$, there are no peaks indicative of either oxide or sulfide in the Sb spectrum and only the bulk metal peaks are present at $527.5 \mathrm{eV}$ and $537 \mathrm{eV}$ (Figure 8f). Furthermore there is no ${ }_{480} \mathrm{O} 1 \mathrm{~s}$ peak at $532 \mathrm{eV}$, and the $\mathrm{C}$ 1s peak is at background levels. A new peak 
appears at about $541 \mathrm{eV}$ near the $\mathrm{Sb} 3 \mathrm{~d}$ peaks due to a surface plasmon loss that is characteristic of a clean surface [12. The ET layer desorbed at a moderate temperature leaving a clean surface. Assuming the desorption process is first order, an estimate of $60-70 \mathrm{~kJ} /$ mole is obtained for the activation energy to remove the thiol from the surface [45]. Although we do not have data on GaAs for comparison, this relatively low activation energy demonstrates the importance of the strength of attachment between the alkanethiolate and the substrate, and ultimately the performance of the self-assembled layer to chemically passivate the surface and serve as a diffusion barrier.

\section{Conclusions}

The effect of solvent polarity, immersion time, and acid concentration in the last surface preparation step were studied in the formation of a 1-eicosanethiolate self-assembled monolayer on $\operatorname{InSb}(100)$. XPS showed that the layers formed in polar solvents such as ethanol and isopropanol slowed reoxidation of the surface after cleaning, while chloroform and toluene produced poor quality layers that oxidized immediately when exposed to air. Finishing the surface with a dip in $1 \mathrm{M} \mathrm{HCl}$ and carrying over a thin liquid layer into the thiol solution reduced oxide regrowth as did extending immersion time from $20 \mathrm{~min}$ to $20 \mathrm{~h}$ in the thiol. The eicosanethiolate layer was partially ordered based on ATR-FTIR. Although the $\operatorname{InSb}(100)$ substrate was rough on an atomic scale, ordering of the thiol and the cohesiveness of the layer were not improved on the smoother InSb(111)B surface based on the kinetics of reoxidation when the surfaces were exposed to air. Support for weaker bonding is shown by the complete desorption of the layer when the surface was heated to about $225^{\circ} \mathrm{C}$ in vacuum. The lower atomic density of the InSb surface that provides points of attachment for a protective layer and the highly reactive substrate due to the narrow bandgap suggest that molecules that interact more strongly than alkanethiolates or that make more than one bond to the surface or to each other may be needed to chemically passivate the surface of InSb. 


\section{Acknowledgments}

YC was partially supported by a fellowship from the National Council of Science and Technology (CONACYT) in Mexico.

\section{References}

[1] I. Vurgaftman, J. R. Meyer, L. R. Ram-Mohan, Band Parameters for III-V Compound Semiconductors and Their Alloys, J. Appl. Phys. 89 (11) (2001) $5815-5875$.

[2] A. Rogalski, J. Piotrowski, Intrinsic Infrared Detectors, Prog. Quantum. Electron. 12 (1988) 87-289.

[3] A. Rogalski, Infrared Detectors: Status and Trends, Prog. Quantum. Electron. 27 (2-3) (2003) 59-210.

[4] J. A. del Alamo, Nanometre-Scale Electronics with III-V Compound Semiconductors, Nature 479 (10677) (2011) 317-323.

[5] R. Chau, S. Datta, A. Majumdar, Opportunities and Challenges of III-V Nanoelectronics for Future High-Speed, Low-Power Logic Applications, in: Proc. IEEE Compound Semicond. Integr. Circuit Symp. (CSIS) Tech. Dig., 2005, pp. 17-20.

[6] D. Aureau, R. Chaghi, I. Gerard, H. Sik, J. Fleury, A. Etcheberry, Wet Etching of InSb Surfaces in Aqueous Solutions: Controlled Oxide Formation, Appl. Surf. Sci. 276 (2013) 182-189.

[7] L. L. Chang, W. E. Howard, Surface Inversion and Accumulation of Anodized InSb, Appl. Phys. Lett. 7 (8) (1965) 210-212.

[8] L. Haworth, J. Lu, D. I. Westwood, J. E. MacDonald, Atomic Hydrogen Cleaning, Nitriding and Annealing InSb (100), Appl. Surf. Sci. 166 (1-4) (2000) 253-258. 

diani, R. Tessler, R. Edrei, Hydrogen and Thermal Deoxidations of InSb and GaSb Substrates for Molecular Beam Epitaxial Growth, J. Vac. Sci. Technol., A 25 (4) (2007) 736-745.

[10] R. Tessler, C. Saguy, O. Klin, S. Greenberg, E. Weiss, R. Akhvlediani, R. Edrei, A. Hoffman, R. Tessler, C. Saguy, Oxide-Free InSb (100) Surfaces by Molecular Hydrogen Cleaning, Appl. Phys. Lett. 88 (3) (2006) 031918.

[11] F. L. Lie, W. Rachmady, A. J. Muscat, Oxide Removal and Selective Etching of In From $\mathrm{InSb}(100)$ with $\mathrm{TiCl}_{4}$, J. Phys. Chem. C 115 (40) (2011) 19733-19740.

${ }_{545}$ [12] F. L. Lie, W. Rachmady, A. J. Muscat, A Comparison of Liquid and Gas Phase Surface Preparation of III-V Compound Semiconductors for Atomic Layer Deposition, Microelectron. Eng. 86 (2) (2009) 122-127.

[13] J. F. Dorsten, J. E. Maslar, Y. Zhang, T. B. Rauchfuss, P. W. Bohn, S. Agarwala, I. Adesida, C. Caneau, R. Bhat, Self-Assembled Monolayers of Lewis Bases: Effects on Surface and Interfacial Electronic Properties in III-V Optical Semiconductors, Proc. SPIE 2125 (1994) 51-58.

[14] M. Y. Pines, O. M. Stafsudd, Surface Effects in n-Type InSb Photoconductors, Infrared Phys. 19 (5) (1979) 559-561.

[15] A. M. Emel'yanov, N. A. Sobolev, S. Pizzini, Effect of Surface State Density on Room Temperature Photoluminescence From $\mathrm{Si}_{-} \mathrm{SiO}_{2}$ Structures in the Range of Band-To-Band Recombination in Silicon, Semiconductors 36 (11) (2002) 1225-1226.

[16] C. J. Sandroff, R. N. Nottenburg, J. C. Bischoff, R. Bhat, Dramatic Enhancement in the Gain of a GaAs/AlGaAs Heterostructure Bipolar Transistor by Surface Chemical Passivation, Appl. Phys. Lett. 51 (1) (1987) $33-35$. 
[17] V. N. Bessolov, M. V. Lebedev, Chalcogenide Passivation of III-V Semiconductor Surfaces, Semiconductors 32 (11) (1998) 1141-1156.

[18] J. C. Ho, R. Yerushalmi, Z. A. Jacobson, Z. Fan, R. L. Alley, A. L. I. Javey, Controlled Nanoscale Doping of Semiconductors via Molecular Monolayers, Nat. Mater. 7 (January) (2008) 62-67.

[19] P. D. C. King, T. D. Veal, M. J. Lowe, C. F. McConville, Surface Electronic Properties of Clean and S-terminated InSb(001) and (111)B, J. Appl. Phys. 104 (8) (2008) 083709.

[20] T. V. Lvova, M. S. Dunaevskii, M. V. Lebedev, A. L. Shakhmin, I. V. Sedova, S. V. Ivanov, Chemical Passivation of InSb (100) Substrates in Aqueous Solutions of Sodium Sulfide, Semiconductors 47 (5) (2013) 721727.

[21] D. M. Zhernokletov, H. Dong, B. Brennan, J. Kim, R. M. Wallace, Optimization of the Ammonium Sulfide $\left(\mathrm{NH}_{4}\right)_{2} \mathrm{~S}$ Passivation Process on InSb(111)A, J. Vac. Sci. Technol., B 30 (4) (2012) 04E103.

[22] T. V. Lvova, A. L. Shakhmin, I. V. Sedova, M. V. Lebedev, Sulfur Passivation of $\operatorname{InSb}(100)$ Surfaces: Comparison of Aqueous and Alcoholic Ammonium Sulfide Solutions Using X-Ray Photoemission Spectroscopy, Appl. Surf. Sci. 311 (2014) 300-307.

[23] S. R. Lunt, G. N. Fiyba, P. G. Santangelo, N. S. Lewis, Chemical Studies of the Passivation Using Sulfides and Thiols of GaAs Surface Recombination, J. Appl. Phys. 70 (12) (1991) 7449-7467.

[24] X. Huang, J. J. Dubowski, Solvent-Mediated Self-Assembly of Hexadecanethiol on GaAs(001), Appl. Surf. Sci. 299 (2014) 66-72.

[25] C. D. Bain, A New Class of Self-Assembled Monolayers: Organic Thiols on Gallium Arsenide, Adv. Mater. 4 (9) (1992) 591-594. 
[26] C. L. McGuiness, D. Blasini, J. P. Masejewski, S. Uppili, O. M. Cabarcos, D. Smilgies, D. L. Allara, Molecular Self-Assembly at Bare Semiconductor Surfaces: Characterization of a Homologous Series of $n$-Alkanethiolate Monolayers on GaAs(001), ACS Nano 1 (1) (2007) 28-32.

[27] C. L. McGuiness, G. A. Diehl, D. Blasini, D.-M. Smilgies, M. Zhu, N. Samarth, T. Weidner, N. Ballav, M. Zharnikov, D. L. Allara, Molecular Self-Assembly at Bare Semiconductor Surfaces: Cooperative Substrate-Molecule Effects in Octadecanethiolate Monolayer Assemblies on GaAs(111), (110), and (100), ACS Nano 4 (6) (2010) 3447-3465.

[28] F. Yamada, S. Arakawa, I. Kamiya, Control of Surface Morphology and Electronic Properties of III-V Semiconductors Using Molecular Modification, J. Vac. Sci. Technol., B 28 (4) (2010) C5F28.

[29] P. Arudra, G. M. Marshall, N. Liu, J. J. Dubowski, Enhanced Photonic Stability of GaAs in Aqueous Electrolyte Using Alkanethiol Self-Assembled Monolayers and Postprocessing with Ammonium Sulfide, J. Phys. Chem. C 116 (4) (2012) 2891-2895.

[30] X. Huang, N. Liu, K. Moumanis, J. J. Dubowski, Water-Mediated SelfAssembly of 16-Mercaptohexadecanoic Acid on GaAs (001), J. Phys. Chem. C 117 (29) (2013) 15090-15097.

[31] Y. Contreras, A. J. Muscat, Passivation of $\operatorname{InSb}(100)$ with 1-Eicosanethiol Self-Assembled Monolayers, Sol. State. Phenom. 219 (2015) 59-62.

[32] E. A. Costner, B. K. Long, C. Navar, S. Jockusch, X. Lei, P. Zimmerman, A. Campion, N. J. Turro, C. Grant Willson, Fundamental Optical Properties of Linear and Cyclic Alkanes: VUV Absorbance and Index of Refraction, J. Phys. Chem. A 113 (33) (2009) 9337-9347.

[33] W. Haynes, Handbook of Chemistry and Physics, 96th Edition, CRC Press, 1992. 
[34] J. P. Danehy, K. N. Parameswaran, Acidic Dissociation Constants of Thiols, J. Chem. Eng. Data 13 (3) (1968) 386-389.

[35] G. Nesher, A. Vilan, H. Cohen, D. Cahen, F. Amy, C. Chan, J. Hwang, A. Kahn, Energy Level and Band Alignment for GaAs-Alkylthiol Monolayer-Hg Junctions from Electrical Transport and Photoemission Experiments., J. Phys. Chem. B 110 (29) (2006) 14363-14371.

[36] C. L. McGuiness, A. Shaporenko, C. K. Mars, S. Uppili, M. Zharnikov, D. L. Allara, Molecular Self-Assembly at Bare Semiconductor Surfaces: Preparation and Characterization of Highly Organized Octadecanethiolate Monolayers on GaAs(001), J. Am. Chem. Soc. 128 (15) (2006) 5231-5243.

[37] H. A. Budz, M. C. Biesinger, R. R. LaPierre, Passivation of GaAs by Octadecanethiol Self-Assembled Monolayers Deposited from Liquid and Vapor Phases, J. Vac. Sci. Technol., B 27 (2) (2009) 637.

[38] T. Baum, S. Ye, K. Uosaki, Formation of Self-Assembled Monolayers of Alkanethiols on GaAs Surface with in Situ Surface Activation by Ammonium Hydroxide, Langmuir 15 (25) (1999) 8577-8579.

[39] S. D. Moré, H. Graaf, M. Baune, C. Wang, T. Urisu, Influence of Substrate Roughness on the Formation of Aliphatic Self-Assembled Monolayers (SAMs) on Silicon(100), Jpn. J. Appl. Phys. 41 (2002) 4390-4394.

[40] J. J. Dubowski, O. Voznyy, G. M. Marshall, Molecular Self-Assembly and Passivation of GaAs (001) with Alkanethiol Monolayers: A View Towards Bio-Functionalization, Appl. Surf. Sci. 256 (19) (2010) 5714-5721.

[41] G. Sareminia, F. Zahedi, S. Eminov, A. Karamian, Cleaning Method of InSb [111] B of n-InSb [111] A/B for the Growth of Epitaxial Layers by Liquid Phase Epitaxy, J. Semicond. 32 (5) (2011) 056001.

[42] J. Hill, J. Murray, The Solution Calorimetric Determination of the Standard Formation Enthalpies of Metal Dithiocarbamate Complexes: a Review, Rev. Inorg. Chem. 13 (3) (1993) 183-198. 
[43] J. A. Dean, Lange's Handbook of Chemistry, 15th Edition, McGraw Hill, Inc., 1999.

${ }_{645}^{6444}$ R. O. Jones, G. Seifert, Cage Molecules Containing Elements of Groups V and VI. I. Structure Determinations Using Simulated Annealing, J. Chem. Phys. 96 (4) (1992) 2942-2950.

[45] P. A. Redhead, Thermal Desorption of Gasses, Vacuum 12 (1962) 203-211. 


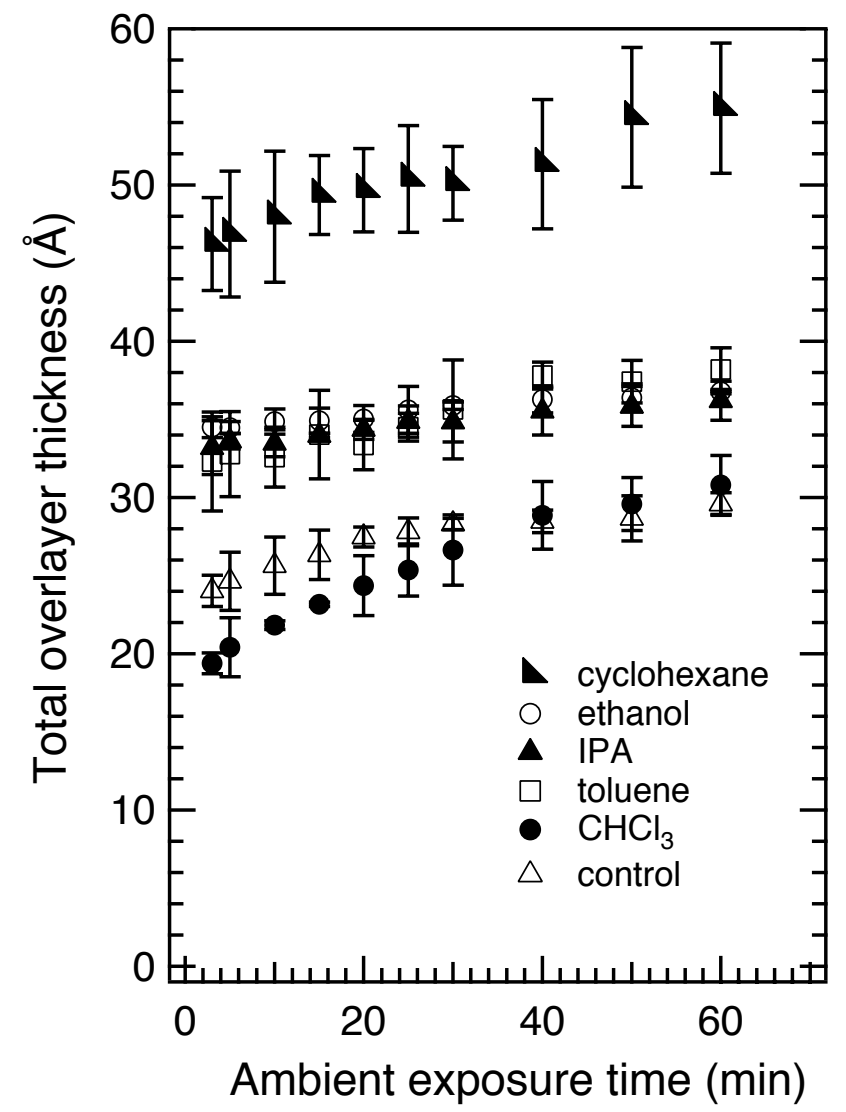

Figure 1: Thickness of the overlayer (ET, InSb oxides, or both) on $\operatorname{InSb}(100)$ measured by ellipsometry after oxide etching finishing in $\mathrm{HCl}$ and 20 min immersions in $0.1 \mathrm{mM} \mathrm{ET}$ dissolved in the solvents shown. The control sample was cleaned and immersed in ethanol without ET. 


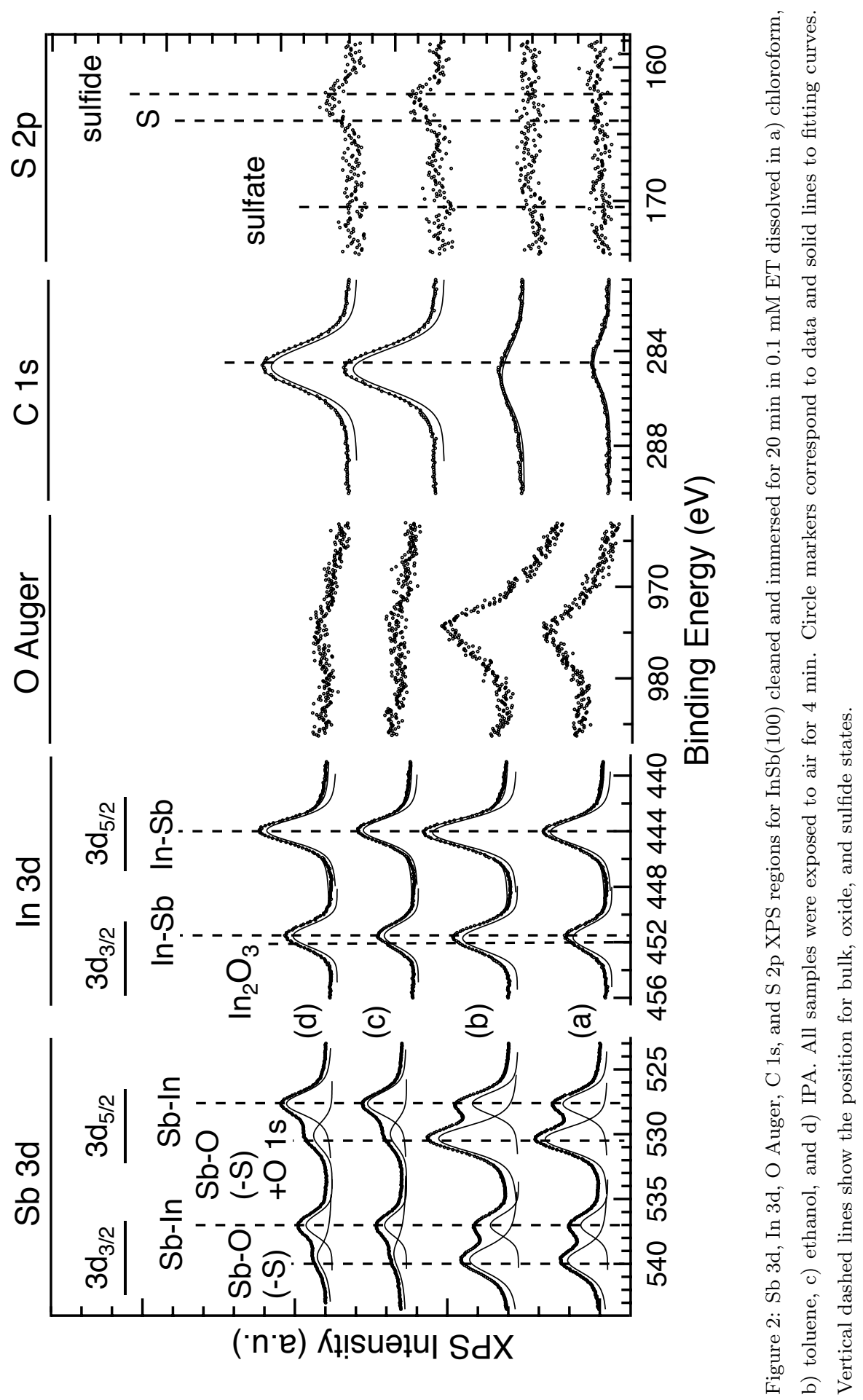




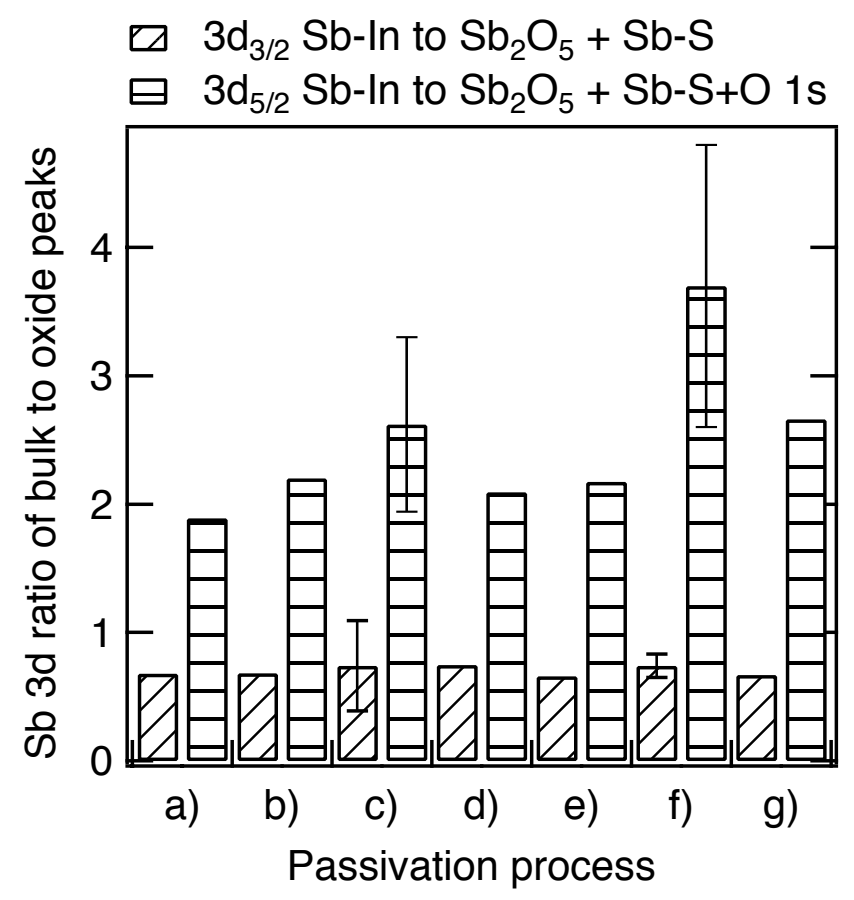

Figure 3: Ratio of the XPS peak areas in the $\mathrm{Sb} 3 \mathrm{~d}$ region after an $\mathrm{HCl}$ finishing step at concentrations of a) $0.1 \mathrm{M}$, b) $0.5 \mathrm{M}$, c) $1.0 \mathrm{M}$, d) $2.0 \mathrm{M}$ followed by a 20 min thiol deposition; e) $1.0 \mathrm{M} \mathrm{HCl}$ last and acid added to the thiol solution followed by a 20 min thiol deposition; $1.0 \mathrm{M} \mathrm{HCl}$ last step followed by a f) $20 \mathrm{~h}$ and a g) $48 \mathrm{~h}$ thiol deposition. All samples were exposed to atmosphere for $3 \mathrm{~min}$ before analysis. 


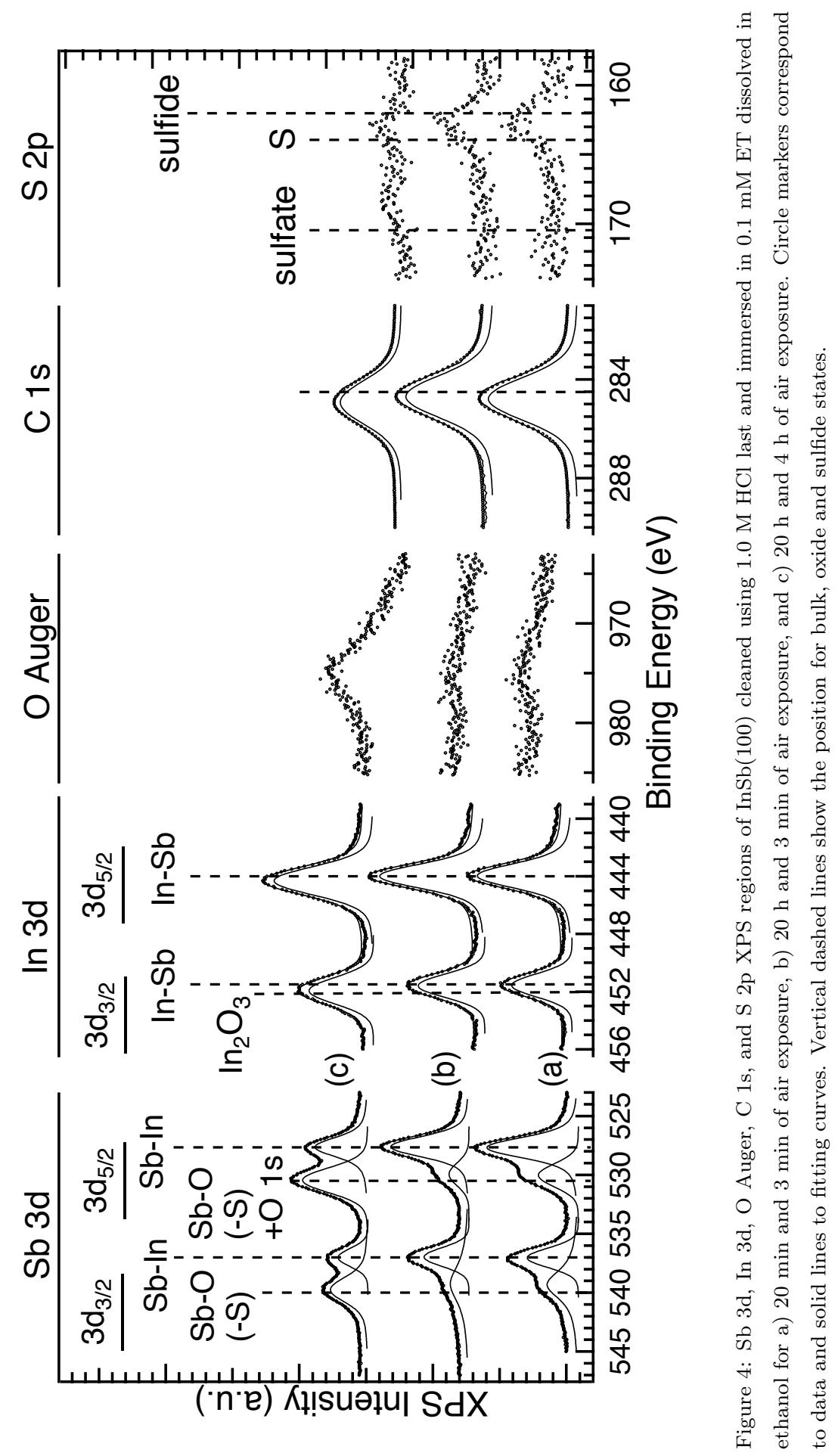




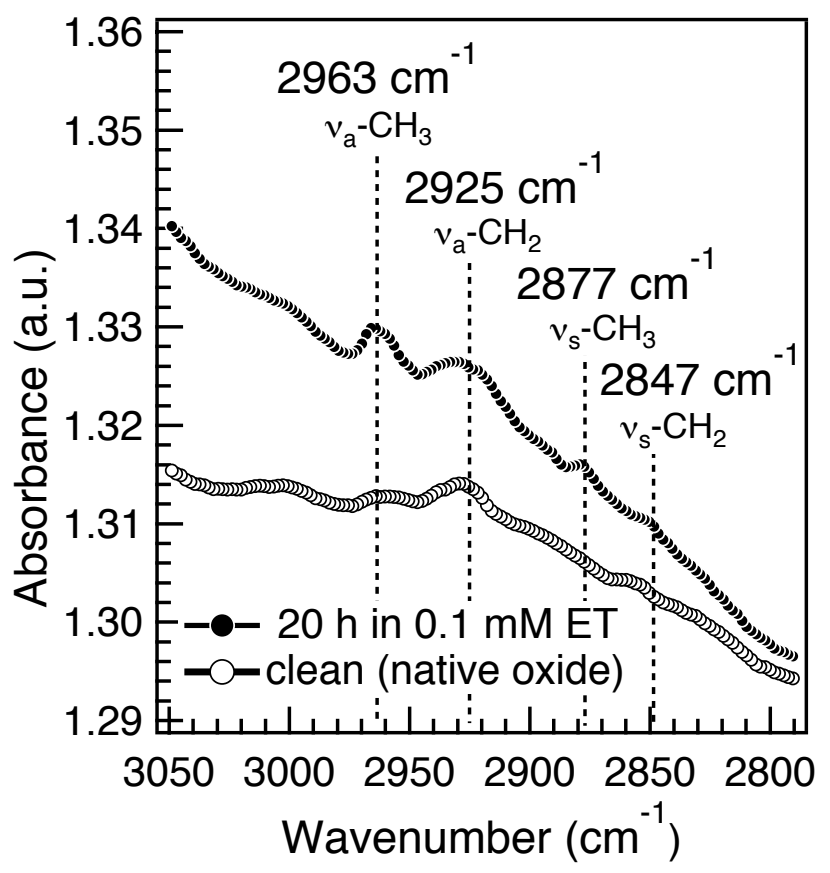

Figure 5: Attenuated total reflection FTIR spectra of $\operatorname{InSb}(100)$ that was sequentially cleaned and finished in $\mathrm{HCl}$ : clean control surface on which an oxide was regrown and after the $20 \mathrm{~h}$ alkanethiolate layer deposition process. Both samples were exposed to atmosphere for approximately $10 \mathrm{~min}$ after the last liquid phase steps.

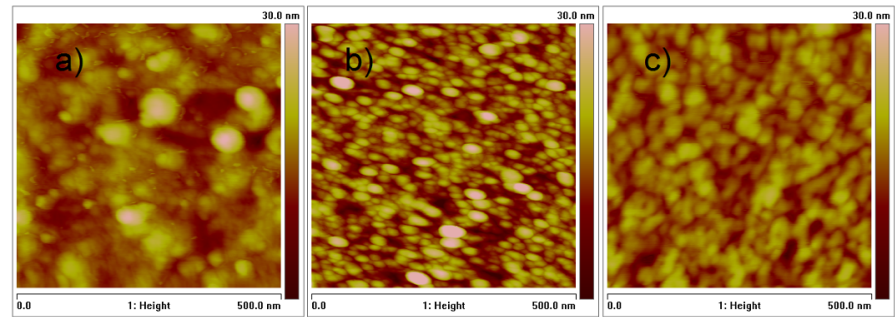

Figure 6: AFM images of $\operatorname{InSb(100)}$ a) as received (2.3 $\pm 0.2 \mathrm{~nm} \mathrm{RMS})$, b) after sequential cleaning finishing in $\mathrm{HCl}$ and reoxidation in atmosphere $(3.8 \pm 1.2 \mathrm{~nm})$, and c) after sequential cleaning, immersion for $20 \mathrm{~h}$ in $0.1 \mathrm{mM} \mathrm{ET}$, and exposed to air for $20 \mathrm{~min}$ ( $2.8 \mathrm{~nm}$, single measurement). 


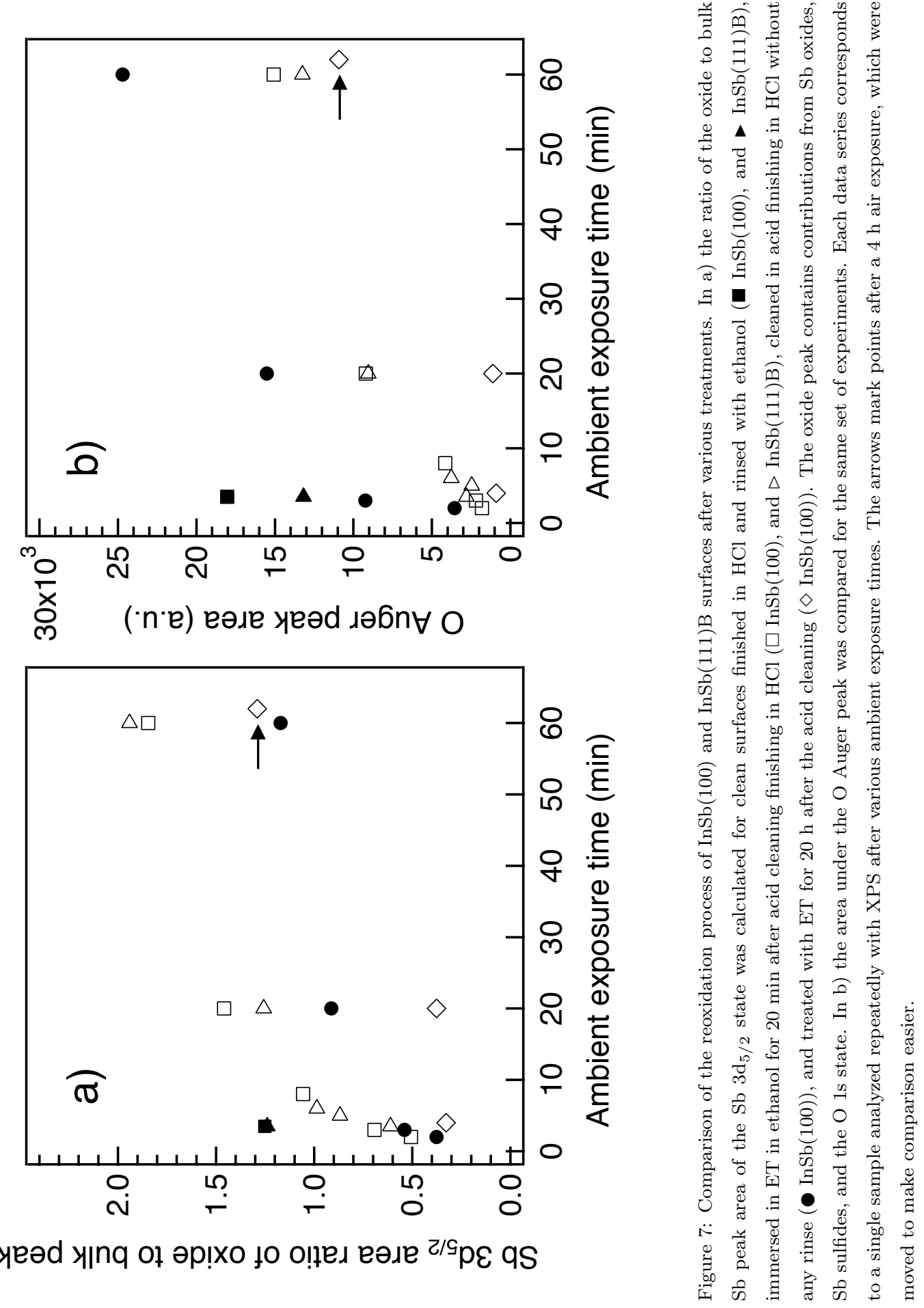



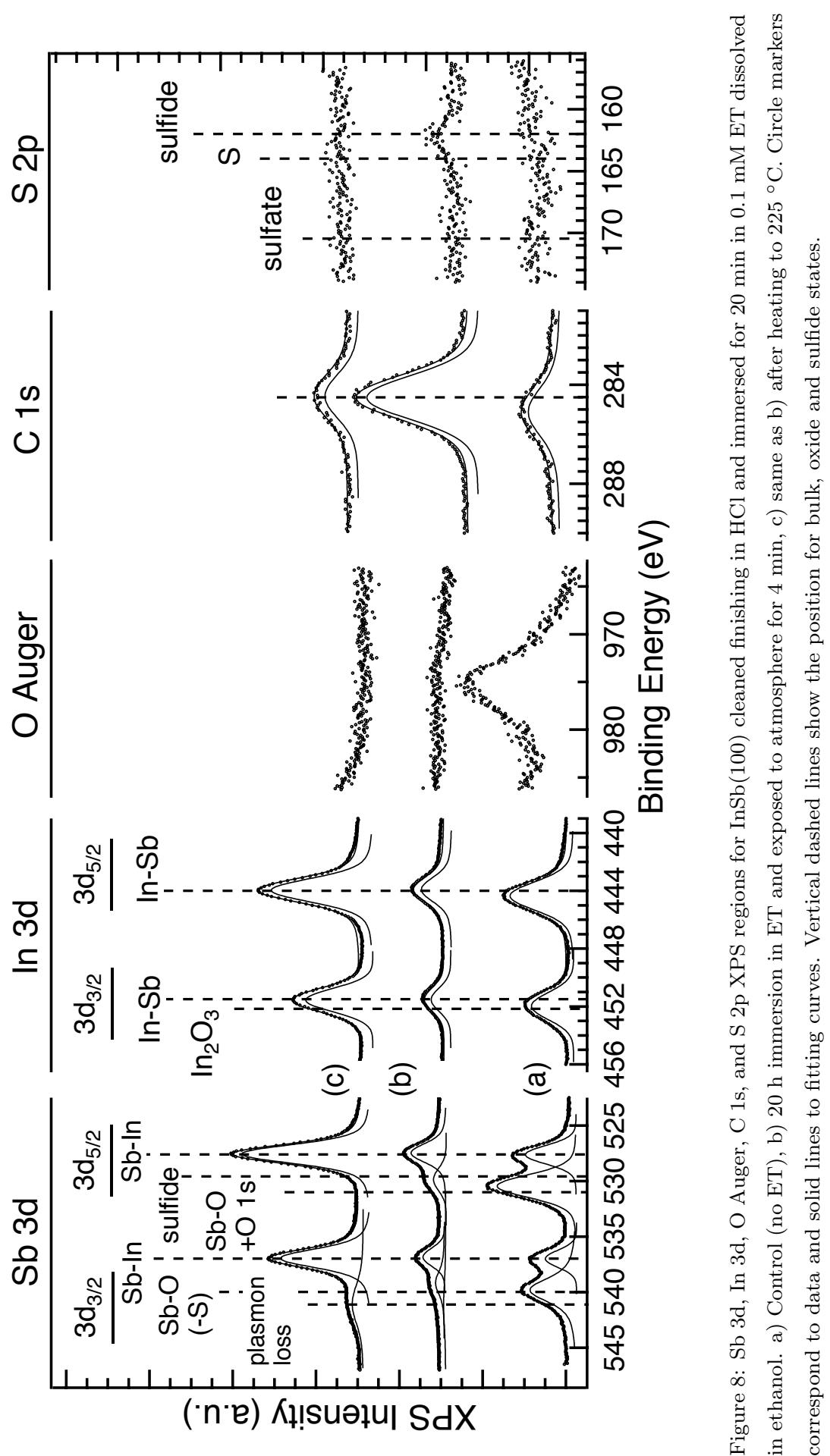